Brit. J. industr. Med., 1963, 20, 32.

\title{
THE EYE AND HYDROGEN SULPHIDE
}

\author{
BY \\ R. W. R. BEASLEY \\ From the Medical Department of the Southern Gas Board, Southampton
}

(RECEIVED FOR PUBLICATION JULY 5, 1962)

An incident in which five men were exposed to hydrogen sulphide and steam is described. Three of the men developed delayed eye effects, and a review of the literature supports the view that these effects were due to hydrogen sulphide.

An incident occurred in which five men were exposed to hydrogen sulphide. The part of the plant in which the incident took place consisted of a condenser in the form of a continuous pipe. Its purpose was to cool and condense vapours of ammonia, carbon dioxide, hydrogen sulphide, and water derived from the distillation of crude ammoniacal liquor in order to prepare concentrated ammoniacal liquor.

Due to certain abnormal conditions, ammonium salts had crystallized and blocked the condenser. In order to free the obstruction several of the U-bends were removed and steam was forced through the pipes to dissolve and flush out the obstructing crystalline deposit. The complete plant was in a well-ventilated building with a lofty roof. The condenser pipes were some 10 to $15 \mathrm{ft}$. from the ground and surrounded by a gallery approached from ground level by a fixed ladder attached to the gallery at the side adjacent to the condenser U-bends. Anyone climbing this ladder would be confronted with the open condenser pipes as many of the U-bends had been removed for the purpose of steaming described above.

The ammonium salts in the deposit consisted of about one-third ammonium sulphide and two-thirds ammonium carbonate. The process of steaming caused these salts to decompose into ammonia, carbon dioxide, and hydrogen sulphide.

\section{Case Reports}

This plant is without previous history of trouble, apart from an occasional ammonia eye splash. An account is given below of the five men who came into contact with the plant during this period of repairs.

Case 1. - The worst affected was a 52-year-old maintenance fitter's mate who, for about four weeks, had spent a considerable time and proportion of his working week on the plant. After a Saturday afternoon shift he was conscious of a gritty sensation in both eyes, but was careful not to rub them. He made no mention of these symptoms to anyone. On leaving the works at the end of this shift he noticed that all the street lights were blurred and surrounded by rainbow rings. He experienced difficulty in driving his car home as the head-lamps of approaching vehicles dazzled him badly, and appeared to be dumb-bell shaped and also surrounded by rainbow rings. At this time there was some retro-orbitalaching. When he arrived home his eye-lids went into spasm and were almost impossible to open for between two and three hours. When he finally was able to open his eyes, he described them as being very red and inflamed in appearance and feeling heavy and tired. The next morning (Sunday) he was due at work on an early shift. Driving back to the works before daylight was difficult because of the distortion, blurring, and rainbow ring effect around vehicle headlamps. This was similar to that experienced the night before but far more severe. During the hours of daylight at work his vision was hazy but the gritty discomfort still present in his eyes gradually receded. The next morning (Monday, 36 hours after the onset of symptoms) he was without complaint.

Throughout the next few days he remained symptomfree until the Thursday, when the gritty sensation in his eyes returned, and in the evening the rainbow vision was also experienced, neither of these symptoms being as severe as before. Hazy vision also occurred in the hours of daylight but this again was not as severe as on the previous occasion. When arriving home after work on this Thursday blepharospasm occurred, duration unrecorded, but appears not to have been as severe as the former episode. Throbbing pains in his eyes troubled him for the latter part of his working day on this occasion. By Friday morning no symptoms remained, and on examination the following Monday there were no physical signs and he was completely without symptoms.

Case 2.-A 57-year-old maintenance fitter worked on the plant for the same length of time as Case 1. On the 
Thursday that Case 1 experienced his second series of symptoms, Case 2 became conscious of hazy vision which he described as being "as though peering through a silk screen", rainbow rings surrounding street lamps, and a gritty sensation in both eyes. There was no blepharospasm or aching, and by the next morning he was completely symptom-free.

Case 3.-A 45-year-old assistant works engineer had made many visits to the plant throughout the four-week period of maintenance and repairs, but during the latter half of this time had spent an average of four to five hours a day there. At the end of work on the last day he noticed that street lights in the middle distance were surrounded by rainbow rings. Generally, his vision was hazy, and he described it "as though looking through silk". He suffered no discomfort or blepharospasm, and the visual phenomena did not return.

TABLE

SUMMARY OF SYMPTOMS

\begin{tabular}{|c|c|c|c|c|c|}
\hline $\begin{array}{l}\text { Case } \\
\text { No. }\end{array}$ & $\begin{array}{c}\text { Orbital } \\
\text { Pain } \\
\text { or Ache }\end{array}$ & $\begin{array}{c}\text { Gritty } \\
\text { Sensa- } \\
\text { tion }\end{array}$ & $\begin{array}{c}\text { Hazy } \\
\text { Vision }\end{array}$ & $\begin{array}{c}\text { Rainbow } \\
\text { Phenomena } \\
\text { in Artificial } \\
\text { Light }\end{array}$ & $\begin{array}{l}\text { Blepharo- } \\
\text { spasm }\end{array}$ \\
\hline $\begin{array}{l}1 \\
2 \\
3\end{array}$ & $\begin{array}{l}\text { Yes } \\
\text { No } \\
\text { No }\end{array}$ & $\begin{array}{l}\text { Yes } \\
\text { Yes } \\
\text { No }\end{array}$ & $\begin{array}{l}\text { Yes } \\
\text { Yes } \\
\text { Yes }\end{array}$ & $\begin{array}{l}\text { Yes } \\
\text { Yes } \\
\text { Yes }\end{array}$ & $\begin{array}{l}\text { Yes } \\
\text { No } \\
\text { No }\end{array}$ \\
\hline
\end{tabular}

Unfortunately, none of these patients complained at the time of the occurrence, so that there was no opportunity for examination.

Two further men, a 32-year-old laboratory technician and a 37-year-old assistant works superintendent, spent several long periods in the plant and remained entirely free from symptoms.

\section{Discussion}

The immediate effect of ammonia on the eye is conjunctival irritation. The delay in onset of symptoms in the present cases and, in Case 1, the build-up in symptoms after exposure, are not typical of ammonia. The only other contaminant in the atmosphere in this plant was very small quantities of hydrogen sulphide, together with a fair amount of steam.

Hunter (1955) mentions lachrymation, photophobia, pain, chemosis, and eversion of the eye-lids as effects of hydrogen sulphide on the eye. He also indicates rainbow vision as a warning of the onset of keratitis from hydrogen sulphide. Rapid recovery within a few days is said to be usual.

Nyman (1954), in a discussion on the treatment of hydrogen sulphide eye inflammation with cortisone, mentions acute conjunctivitis as being the commonest eye effect, and states that some patients develop keratitis. Nyman also mentions that steam may be responsible for increasing the severity of symptoms due to hydrogen sulphide in the eye. Troisi (1953) describes eight cases of keratitis and seven of conjunctivitis caused by hydrogen sulphide liberated from polluted water used in a factory. An interesting description is given by Larsen (1944) of a tunnelling project in which cases of eye reactions to the hydrogen sulphide in the atmosphere occurred. The symptoms described by Larsen were smarting eyes, a sensation of grains of sand in the eyes, and haloes round artificial lights. The lack of symptoms while the men were actually at work are reported, and in general symptoms were not found to be severe until the worker reached the surface, where, during daylight, the photophobia caused severe blepharospasm.

Larsen described the cornea as granular in appearance and covered with pin-point enflamed blisters over the area least protected by the eye-lids. No fluorescein staining was found at this stage, but later a stained band was found. It was at this latter stage (generally a day after the exposure) that the symptoms were most severe, Another author, Frantisek (1950), describes rainbow haloes, pain, blepharospasm, and red eyes occurring in a sugar beet factory (cf. Troisi, 1953) due to hydrogen sulphide liberated from water-containing sulphites. Humidity is stressed by Frantisek (1950) as being an important contributory factor. Sjögren (1939) describes the rainbow effects, photophobia, and burning sensation, all of which were generally worse a day or so after exposure. His cases occurred in a paper mill using lake water with high hydrogen sulphide content for rinsing processes. Blepharospasm and dimness of vision were also mentioned.

The occurrence, amongst caisson workers in an atmosphere of hydrogen sulphide, of painful eyes showing diffuse vesicles and occasional epithelial defects, all of which recovered in a few days, is described by Hartmann (1937). Rubin and Arieff (1945), in a clinical study of low grade carbon disulphide and hydrogen sulphide exposures, believe diminution and loss of corneal reflexes are frequent and diagnostically valuable. This may support Larsen's (1944) view that the slight anaesthetic effect of the hydrogen sulphide reduces symptoms during exposure and is responsible for the delayed effect.

A reference to eye inflammation as the only symptom of incipient hydrogen sulphide poisoning is made by Howes (1944) who described soreness of the eyes, severe photophobia, and tears that burned the cheeks. Howes writes: "This note is submitted because eye trouble, such as that described, may be a timely warning of possible serious or fatal poisoning and does not seem to be sufficiently recognised as an early symptom of hydrogen sulphide poisoning". 
McDougall and Garland (1954) have recorded the eye effects of hydrogen sulphide in a paper describing hydrogen sulphide gas poisoning in New Zealand in a highly active thermal area. They state that early symptoms of poisoning are as though soapy water had entered the eyes, this feeling being followed by a sensation of sand in the eyes and haloes around artificial lights. They go on to say that blindness may supervene and prevent the patient working for several days.

\section{Conclusion}

Although no clinical details of the appearance of the eyes of the three cases observed are available, the literature reviewed above is in agreement with the symptoms attributed to hydrogen sulphide in the present incident. In this instance no hydrogen sulphide problem had been thought to exist and its discovery through these eye effects was considered a forewarning of more serious possibilities, and preventive action was taken at once.

My thanks go to the Works' sister, Mrs. B. M. Dunne, for drawing attention to the Cases, to the Works Superintendent at that time, Mr. E. L. Faulkner and to his assistant, Mr. R. G. Weston, for helping in the investigation, and to the patients. Mr. W. F. Thorne has been most helpful with chemical details.

My thanks are due to the Chairman of the Southern Gas Board, Mr. A. F. Hetherington, for permission to publish this report.

\section{REFERENCES}

Frantisek, M. V. (1950). Čs. Oftal., 6, 5.

Hartmann, K. (1937). Klin. Mbl. Augenheilk., 99, 456.

Hunter, D. (1955). The Diseases of Occupations, 1st ed., p. 575. English Universities Press, London.

Howes, H. S. (1944). Analyst, 69, 92.

Larsen, V. (1944). Acta ophthal. (Kbh.), 21, 271.

McDougaill, J. W. G., and Garland, T. O. (1954). N.Z. med.J., 53, 471.

Nyman, H. T. (1954). Industr. Med. Surg., 23, 161.

Rubin, H. H., and Arieff, A. J. (1945). J. industr. Hyg., 27, 123.

Sjögren, H. (1939). Acta ophthal. (Kbh.), 17, 166.

Troisi, F. M. (1953). Med. d. Lavoro, 44, 83 . 